\section{Italian drug problems clarified}

SiR - I should like to make the following comments on the allegations about me in articles on the scandals in the Italian health sector (Nature 364, 562 \& 663; 1993).

(1) My resignation as chief executive officer of Fidia dates back to February 1991 and was totally unrelated to any of the financial difficulties now being experienced by the company. The statement that I was ". . . fired last year following financial difficulties ..." is totally incorrect and without foundation. My resignation was the consequence of a disagreement with the major shareholder regarding the continuity of significant investment in scientific research. Anyone can easily confirm that, under my guidance, Fidia became one of the foremost Italian pharmaceutical enterprises dedicated to advanced research in the neurosciences (see Nature 361, 766; 1993) and was in excellent financial shape up to 1991 .

(2) The joint venture with Georgetown University was undertaken in 1985 to increase the effectiveness of the company's research and development efforts, accepting the challenge of operating directly in the most exacting and competitive scientific environment in the world. The cost of the venture was proportionate to the company's financial resources and represented less than 10 per cent of Fidia's total research and development budget. It is sad to see that some very promising research projects are now being stopped just when they are about to yield significant results to substantiate important medical applications.

(3) In the present state of affairs, it is not up to me to defend the scientific position of gangliosides as remarkable pharmacological tools in nervous tissue repair. However, it is simply not true that ". . . approval was never sought in the US

"Under my management, two of Fidia's ganglioside preparations were released by the US Food and Drug Administration as investigational new drugs for the treatment of disorders of the peripheral nervous system, spinal cord injury and stroke. Encouraging results in some of these areas have been reported ${ }^{1}$.

(4) As regards the alleged association with Guillain-Barre syndrome, it has been pointed out that the coincidence is explainable in terms of a protopathic bias, and accurate epidemiological investigations in Italy have shown the inconsistency of the allegation ${ }^{2,3}$. It remains a mystery why Fidia did not make effective use of the information available to defend its ganglioside preparations against often illinformed and clearly tendentious attacks.

(5) A complete account of my personal involvement in the corruption scandal has been made to the investigating magis- trates. The episode in question dates back to 1990 and refers to a formal application by Fidia to increase the price of a phospholipid preparation which had not been reviewed for over 15 years - in spite of an almost tenfold increase in production cost. Payments were repeatedly invited by the private secretary of the Minister of Health to "keep the application moving". My decision to pay was taken solely in the interests of the company and was in line with that taken by the Italian, as well as multinational, pharmaceutical companies, pressed to make funds available for the financing of political parties, as a condition for the review of otherwise perfectly legitimate applications. Ironically, a new price was never fixed for the phospholipid preparation in question.

This disgraceful situation, which has now come to light thanks to the relentless efforts of the Milan magistrates, played a role in my decision, in 1991 , to found a new pharmaceutical company, Lifegroup, intended to operate exclusively in openmarket conditions. Lifegroup now manufactures and sells drugs not reimbursed by the Italian Public Health Service, and is dedicating substantial resources to scientific research in the areas of neuroimmunology and dermatology. This is the direct consequence of my belief that in Italy only the restoration of free market rules, based on drug quality, free pricing and fair competition, will effectively combat the political conditioning of the market-place and remove from the entrepreneurial environment distortions that damage the whole economic order of the Italian health care sector and do not benefit the ill.

Francesco della Valle

Lifegroup $S p A$,

via della Pieve 10/12,

Padua, Italy

\footnotetext{
1. Geisler, F. H., Dorsey, F. C. \& Coleman, W. P. N. Engt. J. Med. 324, 1829-1838(1991).

2. Paolino, E., Govoni, V., Tola, M. R., Casetta, I. \& Granieri, E. Neuroepidemiology 10, 105-111 (1991).

3. Granieri, E. et al. Neuroepidemiology 10, 161-169 (1991),
}

Alison Abbott writes: I regret the error in the date of Dr Della Valle's resignation from Fidia.

\section{Wrong ideas}

SIR - V. Koliadin (Nature 364, 96;1993) defends Peter Duesberg's repeated querying of the widely accepted hypothesis that HIV causes AIDS, saying: "If a work expresses an unorthodox view, its chance of being published is quite small. As the history of science demonstrates, most landmark works have been at first regarded as wrong and intolerable."

But do scientists accept wrong new ideas more or less often than they reject ideas ultimately proved correct? An article in the British Medical Journal published the day after Koliadin's letter coincidentally addressed this issue. Bernard Dixon reported $(307,137 ; 1993)$ that of the recent analysis by Juan Campanario (Social Studies of Science 23, 342; 1993) of 300 Institute of Scientific Information (ISI) "citation classics", only 5.7 per cent of the authors explicity mentioned difficulties in getting their findings published by peer-reviewed journals. Even allowing for considerable error in reporting and the vagaries of ISI's selection methods, it seems that "most landmark works" are readily considered by the scientific community before their ultimate acceptance, and are not simply regarded as "wrong or intolerable".

Of course Duesberg may end up as part of the 5.7 per cent. But as a working hypothesis, the idea that HIV causes AIDS does not provide a preventive course of action which, when adopted, works. Although it is technically correct to dwell on philosophical niceties, it is to be deplored if such a course inadvertently detracts from human well-being.

\section{Jonathan Cowie}

5 Charlieville Road,

North Heath, Kent DA8 1HJ, UK

\section{Population growth}

SIR - The central theme of your leading article on population growth" was "coercion". The question is: has the West exhausted all other options? Donor assistance for family planning amounts to about $\$ 560$ million annually. This accounts for 1 per cent of all development assistance ${ }^{2}$. According to the United Nations Population Fund ${ }^{3}$, the governments of developing countries ("corrupt governments"?) contribute 75 per cent of the current total expenditure on family planning. Even if the affluent countries do not increase but merely reverse their pattern of assistance from military to development programmes (usually 10:1), the prospects for population growth would become much happier.

What we need most today is understanding rather than coercion and the "white man's burden" approach. More critical appraisal is needed of the available options.

\section{Shashi Kant}

Department of Community Medicine,

\section{R. Murmu}

Department of Surgery,

All India Institute of Medical Sciences,

New Delhi - 110 029, India

1. Nature 362, 379 (1993).

2. Population Reports, Population Information Programme 1-2 (Johns Hopkins University, Baltimore, 1991).

3. United Nations Population Fund. Global Population Assistance Report 1982-1989, 90 (New York, UNFPA, 1991). 